\title{
A 'low-level' explanation for the recent large warming trend over the western Antarctic Peninsula involving blocked winds and changes in zonal circulation
}

\author{
A. Orr, ${ }^{1}$ D. Cresswell, ${ }^{1}$ G. J. Marshall, ${ }^{2}$ J. C. R. Hunt, ${ }^{1}$ J. Sommeria, ${ }^{3}$ C. G. Wang, ${ }^{4}$ \\ and M. Light ${ }^{1}$ \\ Received 25 November 2003; revised 12 January 2004; accepted 28 January 2004; published 18 March 2004.
}

[1] We demonstrate a mechanism whereby the impact of stronger circumpolar westerly winds on the mountains of the Antarctic Peninsula contributes significantly to the enhanced warming trend observed over its western side in the last 50 years. Numerical and laboratory meteorological modelling demonstrate how, when westerly winds impinge on this side, warm air below the height $(1.5-2.0 \mathrm{~km})$ of the Peninsula is advected in a southerly direction. The strength of the annual mean westerly winds has increased by about $15-20 \%$ since the 1960 s, while the modelling results indicate that contemporaneously the air advected to its western side originates from an increasingly northerly (and warmer) location. This gives rise to increased northerlies and a greater transport of warm air into this region. Consequently there is a reduction in the sea-ice extent, further amplifying the local warming. This 'low-level', orographic mechanism for the local climate trend is supported by observational evidence. INDEX TERMS: 3349 Meteorology and Atmospheric Dynamics: Polar meteorology; 3329 Meteorology and Atmospheric Dynamics: Mesoscale meteorology; 3322 Meteorology and Atmospheric Dynamics: Land/atmosphere interactions. Citation: Orr, A., D. Cresswell, G. J. Marshall, J. C. R. Hunt, J. Sommeria, C. G. Wang, and M. Light (2004), A 'low-level' explanation for the recent large warming trend over the western Antarctic Peninsula involving blocked winds and changes in zonal circulation, Geophys. Res. Lett., 31, L06204, doi:10.1029/2003GL019160.

\section{Introduction}

[2] Over the past 50 years the Antarctic Peninsula has experienced a warming trend of $\sim 2.8^{\circ} \mathrm{C}$ in near-surface air temperatures, significantly greater than the global mean warming of $\sim 0.3^{\circ} \mathrm{C}$ [e.g., Vaughan et al., 2001]. This warming is more pronounced on the western side (Figure 1). Changes to the regional oceanic circulation [Hofmann et al., 1996] and the meridional component of the atmospheric circulation [King and Harangozo, 1998; van den Broeke, 2000] have been proposed as mechanisms for this enhanced warming trend.

\footnotetext{
${ }^{1}$ Department of Space and Climate Physics, University College London, London, UK.

${ }^{2}$ British Antarctic Survey, Cambridge, UK.

${ }^{3}$ Laboratoire des Ecoulements Géophysiques et Industriel/CORIOLIS, CNRS, Grenoble, France.

${ }^{4}$ Department of Meteorology, University of Reading, Reading, UK.
}

Copyright 2004 by the American Geophysical Union. 0094-8276/04/2003GL019160
[3] There has been a strengthening of the circumpolar westerly flow around Antarctica by approximately $15-20 \%$ (in the annual mean velocity) at lower levels (i.e., below the height of the Peninsula), as observed in the north of the Antarctic Peninsula by radiosonde data for the period 1969-2000 [Marshall, 2002]. This result is consistent with the trend towards the positive polarity of the Southern Hemisphere Annular Mode (SAM) beginning in the mid1960s [Marshall, 2003], which has been associated with the observed spatial pattern of Antarctic surface warming [Kwok and Comiso, 2002]. This index describes an annular structure in variability with synchronous pressure anomalies of opposite sign above Antarctica and the southern midlatitudes. The positive trend in the SAM indicates an increase in the strength of the circumpolar westerlies. Note that the length of this trend in the SAM is less than the period over which the warming has occured.

[4] We examine whether the interaction of the stronger circumpolar westerly flow with the Antarctic Peninsula could be partly responsible for the recent net warming experienced over its western side.

[5] Schwerdtfeger [1976] noted that the advection of warm maritime air from the southeastern Pacific Ocean to the western Antarctic Peninsula had increased during the 1970's; but he did not relate this to the special features of air flow over/around the Peninsula. This flow is determined by the Froude number $\mathbb{F}$ defined by $U / N H$ (where $U$ is the velocity, $H$ the height of the Peninsula $(\sim 2000 \mathrm{~m})$, and $N$ the atmospheric stability (typically $\left.0.01 \mathrm{~s}^{-1}\right)$ ) and the ratio of $B / L_{R}$ (where $B$ is the length of the Peninsula $(\sim 2000 \mathrm{~km})$ and $L_{R}$ is the Rossby Deformation radius (typically 100$150 \mathrm{~km})$ ). When $\mathbb{F}<0.5$ the flow is blocked at lower levels by the Peninsula [Ólafsson, 2000]. When $B / L_{R}>1$, the Coriolis acceleration deflects the flow to the right (in the Southern Hemisphere) [Smith, 1989; Ólafsson and Bougeault, 1997; Hunt et al., 2001]. If $\mathbb{F} \geq 0.5$ the air flow passes over the Peninsula and descends the other (easterly) side.

[6] The velocity of the circumpolar westerly flow is typically $7 \mathrm{~ms}^{-1}$ at low-level (an elevation of $850 \mathrm{hPa}$ ) [Marshall, 2002], giving $\mathbb{F} \approx 0.35$. Thus warm air below the height of the Peninsula is blocked and advected in a southerly direction along the Peninsula. The trend for stronger zonal winds implies increased blocking at lower levels, resulting in increased northerlies and enhanced warm air advection southwards, contributing to the large surface warming trend along the western Antarctic Peninsula.

[7] This concept is based on the idealised shallow-layer model of Hunt et al. [2004] for stable mesoscale atmo- 


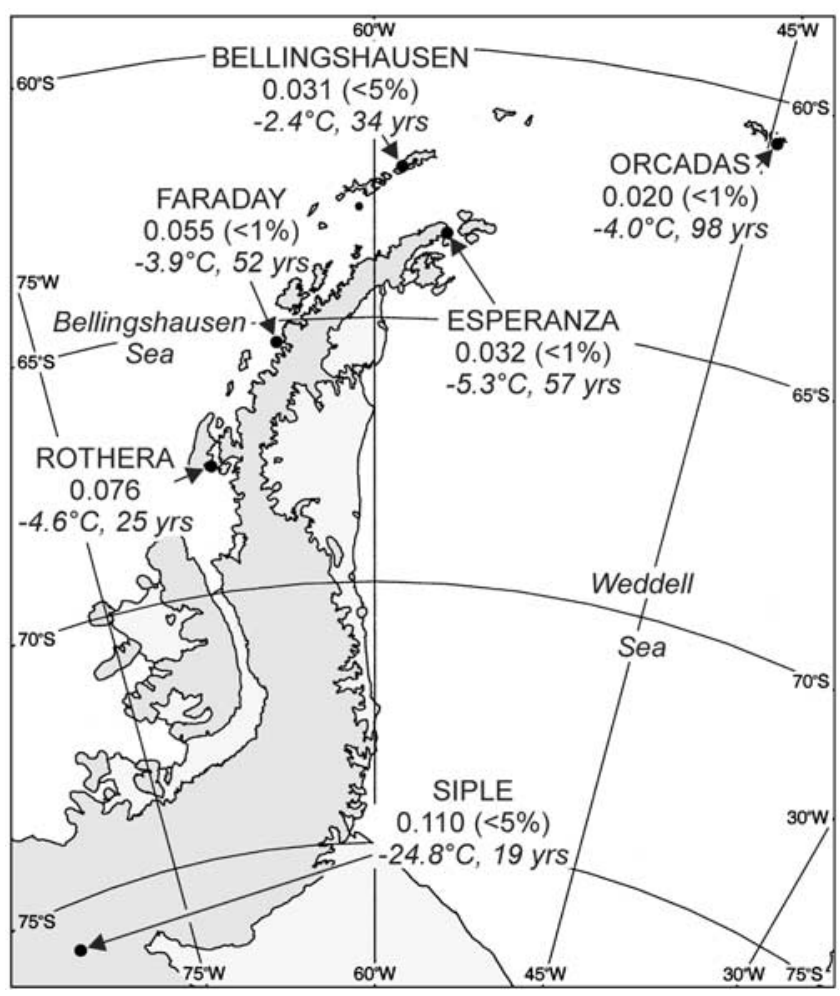

Figure 1. A map of the Antarctic Peninsula region showing temperature information at research stations mentioned in the text. The annual temperature trend is given in ${ }^{\circ} \mathrm{C} \mathrm{yr}^{-1}$, and the statistical significance, if any, given in parantheses. The mean annual temperature and length of the observation record are given in italics.

spheric flows incident on to a 'cape' which is approximate to the Antarctic Peninsula (which also discusses the limitations of numerical weather/climate (NWP) models in capturing these important mesoscale processes). In this paper we present further evidence of this theory using the results of laboratory experiments and numerical mesoscale modelling of westerly flows interacting with the Peninsula.

\section{Laboratory Experiment}

[8] The interaction of westerly zonal winds with the Antarctic Peninsula was studied using a rotating stratified tank $(13 \mathrm{~m}$ in diameter and fluid depth of $60 \mathrm{~cm})$ on the Coriolis turntable, Grenoble, France. The Antarctic Peninsula was represented by a simple 'cape' consisting of a radial barrier (perpendicular to the mean flow) of length perpendicular to the wind $B=100 \mathrm{~cm}$, height $H=10 \mathrm{~cm}$ and width parallel to the flow $D=35-50 \mathrm{~cm}$, abutting onto a bounding wall (parallel to the mean flow) of height $20 \mathrm{~cm}$. The cape was placed on the tank bottom. Westerly and easterly flows over the cape of $1-10 \mathrm{cms}^{-1}$ were driven by either impulsively increasing or decreasing the turntable rotation rate, so that the Froude number $\mathbb{F}$ varied from 0 to 2 .

[9] Figure 2 shows horizontal streamline patterns of lowlevel westerly flow relative to the cape. Here $\mathbb{F} \approx 1 / 3$ and $L_{R}=45 \mathrm{~cm}$ (i.e., $B / L_{R}>1$ ). The upstream flow divides in the horizontal plane when blocked by the cape, with a stagnation point in the flow at $y=y_{S}(y=0$ at the bounding wall and $y=B$ at the tip of the cape). For $0<y<y_{S}$ the streamlines turn to the right along the cape and recirculate in the upwind direction. For $y>y_{S}$ the streamlines turn to the left, flowing around the cape and forming a jet extending downstream and a circulation cell in the lee of the cape. The proportion of the flow recirculating upwind was $y_{S} / B \approx 0.6$. This appeared to depend on the mean upwind flow speed, with more circulating at higher Froude number (as expected theoretically [Hunt et al., 2001]). Because of the lowFroude number, the upper-level flow (i.e., above the height of the cape) passed over the cape with little deflection (not shown). Further experimental runs showed that in all highFroude number flow $(\mathbb{F} \geq 0.5)$ the streamlines pass over the cape and descended on the lee side (not shown).

\section{Numerical Mesoscale Modelling}

[10] The numerical model used in this study is the atmosphere-only UK Met. Office Unified Model, version 4.5 (UM 4.5). The UM is a General Circulation Model (GCM) system designed to run as a climate, global, or limited-area mesoscale model. UM 4.5 implements a nonlinear, hydrostatic set of dynamical equations on a horizontal latitude-longitude grid and a 'hybrid'sigma/pressure coordinate system in the vertical [Cullen, 1993]. Details of the physical parameterizations can be found in Clark and Hopwood [2001]. For the simulations a nested limited-area domain with horizontal resolution of $12 \mathrm{~km}$ and 38 vertical levels was centred over the Antarctic Peninsula. Use of a rotated coordinate pole achieves uniform resolution. Lateral boundary conditions are generated initially from UM 4.5 running as a global model.

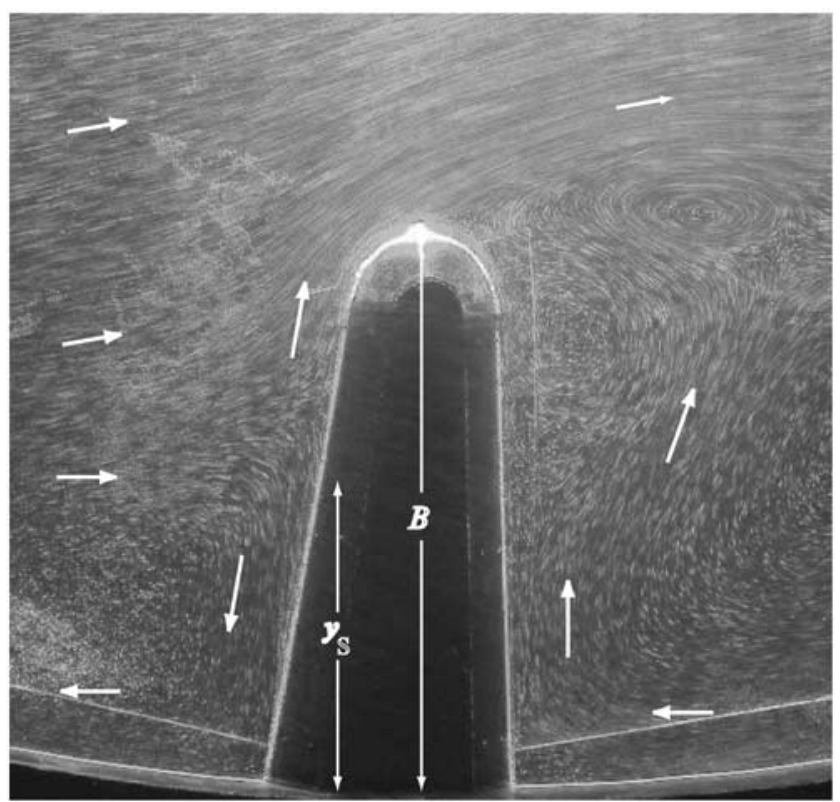

Figure 2. Horizontal streamline photograph of simulated low-level westerly flow (left to right) around a cape in the Southern Hemisphere, with $\mathbb{F} \approx 1 / 3$. The length $y_{S}$ defines the position of the stagnation point from the base of the cape and $B$ is the length of the cape. See color version of this figure in the HTML. 

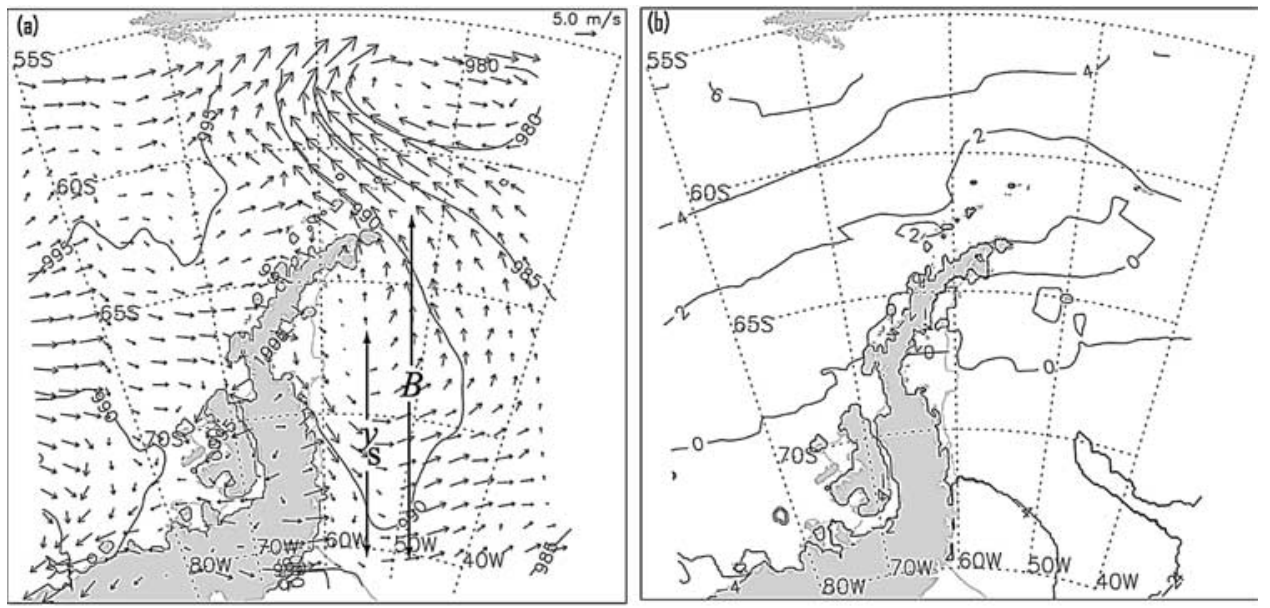

Figure 3. Atmospheric westerly flow over the Antarctic Peninsula at 29 January 2002 06UTC. Computed using UM 4.5 with a horizontal resolution of $12 \mathrm{~km}$. Shown are (a) $10 \mathrm{~m}$-wind speed $\left(\mathrm{ms}^{-1}\right)$ vectors (every 8 grid points) and mean surface level pressure $(\mathrm{hPa})$ and $(\mathrm{b})$ surface temperature $\left({ }^{\circ} \mathrm{C}\right)$. The length $y_{S}$ defines the position of the stagnation point from the base of the Peninsula and $B$ is the length of the Peninsula. See color version of this figure in the HTML.

[11] Figure 3a shows the $10 \mathrm{~m}$-wind speed and surface pressure (hPa) over the Antarctic Peninsula for 29 January 2002 06UTC computed using UM 4.5. The upwind flow is well defined and representative of the westerly flow around Antarctica $(\mathbb{F} \approx 0.3)$. The computations show upstream flow divergence in the horizontal plane with a stagnation point in the flow at $y=y_{S}(y=0$ at the base of the Peninsula and $y=B$ at the tip of the Peninsula). Here $y_{S} / B \approx 0.6$. For $0<y<y_{S}$ the flow moves south along the Peninsula and recirculates in the upwind direction. For $y>y_{S}$ the flow moves north. The beginnings of a jet forming downstream of the Peninsula is rapidly deflected to the north by a low pressure system over the Weddell Sea. The upper level flow passes over the Peninsula with little deflection (not shown).

[12] The general flow field and the location of the stagnation point corresponds closely to the laboratory experiment discussed earlier. Figure $3 \mathrm{~b}$ shows the surface temperature at $10 \mathrm{~m}$, illustrating that relatively warm northerly air $\left(2-4^{\circ} \mathrm{C}\right)$ at low-level is being transported to the Peninsula. As the mean upwind flow speed increases, i.e., as the Froude number increases towards 0.5 , it was found that the stagnation point $y_{S}$ moves north towards the tip of the Peninsula and the size of the recirculating region $\left(y_{S} / B\right)$ increases. When the Froude number exceeds 0.5 the deflection of the flow is reduced and the flow passes over the Peninsula and descends on the downwind side (not shown).

\section{Discussion}

[13] The laboratory experiment and numerical mesoscale simulations show that low-level, low-Froude number $(\mathbb{F}<$ 0.5 ), westerly flow is blocked by the cape/Antarctic Peninsula. As $B / L_{R}>1$ the flow divides in the horizontal plane with some deflected to the right by the Coriolis acceleration and recirculating upwind, and some flowing around the cape and forming a jet extending downstream. The simulations demonstrate that the proportion of the flow recirculating upwind depends on the mean upstream flow speed, with more circulating at higher upstream speeds, and that upper-level, low-Froude number flow is relatively unde- flected by the obstacle. This blocking mechanism is only partially evident from numerical modelling using a coarse horizontal resolution (i.e., NCEP/NCAR reanalysis data, data from UM 4.5 running as a climate model [Connolley and Cattle, 1994]).

[14] This local flow structure interacts with the increased and more frequent circumpolar westerly flow around Antarctica to contribute to the enhanced near-surface warming over the western Antarctic Peninsula. The low-level blocking of the flow here gives rise to northerly winds and greater transport of relatively warm air along the western side (and to a limited extent to the eastern side of the Peninsula) (see Figures 2 and 3). As the velocity of the westerly winds strengthens, since the scale of the recirculating flow region $y_{S} / B$ increases the airstream moving along the western side of the Peninsula originates from a more northerly latitude in the Pacific Ocean. Hence the advected air is increasingly warmer. This hypothesis is supported by the observed increase in precipitation events on the western coast [Turner et al., 1997]. Another observation consistent with the proposed 'low-level' explanation for the Peninsula warming is that Marshall et al. [2002] showed that the mid-tropospheric warming above the north-western Peninsula was only approximately half that recorded at the surface.

[15] During the past few decades the Peninsula surface temperature record shows a warming that increases with southerly latitude [Vaughan et al., 2001; Shuman and Stearns, 2001]. The trend varies from $0.031^{\circ} \mathrm{C} \mathrm{yr}^{-1}$ at $62^{\circ} \mathrm{S}$ to $0.110^{\circ} \mathrm{C} \mathrm{yr}^{-1}$ at $76^{\circ} \mathrm{S}$, as average temperature decreases (cf. Figure 1), consistent with warm air being advected south to progressively colder regions. Associated with the warming trend along the west coast is a decrease in the sea-ice extent [Jacobs and Comiso, 1997], which has the effect of amplifying climatic fluctuations through the ice-albedo feedback mechanism. The proposed changes in warm air advection and the resultant increase in northerlies would reduce sea-ice extent by increasing melting and suppressing the northward expansion of the sea-ice, respectively. 
[16] The blocking-mechanism could explain why King's [1994] observation that annual near-surface temperatures along the western peninsula are more highly correlated with meridional rather than zonal flow over the 1945-90 period. Coincident trends in tropospheric winds above Bellingshausen in the northern Peninsula (where the reduced orography means blocking is less significant) show increases in zonal but not meridional flow [Marshall, 2002]. This dataset also reveals a greater increase in the westerlies during summer than winter during 1969-2000, consistent with the observed changes in the SAM.

[17] In reality, the 'climatological' flow conditions simulated in the laboratory are relatively rare: typically the flow around Antarctica also includes synoptic scale eddies and fronts. Additionally, the laboratory simulations will not capture the complicated interaction between katabatic winds blowing off the Peninsula and the West Antarctic Ice Sheet and the prevailing westerlies, as evident in Figure $3 \mathrm{a}$. Nonetheless, typically, there are north-westerlies affecting the western side of the Peninsula as the Bellingshausen Sea often is a region of strong cyclolysis. This is also consistent with the effects of the topographic barrier, as is the observation of a mean northerly meridional wind component at an elevation of $850 \mathrm{hPa}$ for 11 months of the year, derived from a limited radiosonde dataset from the western coast (Rothera) during 2002-03.

[18] The increase in the strength of the westerlies also makes the probability of high-Froude number flow ( $\mathbb{F} \geq$ $0.5)$ more likely. The laboratory and numerical simulations showed that all high-Froude number flow passes over the Peninsula and descends on the lee (easterly) side [Hunt et al., 2001, 2004], transporting relatively warm air to the eastern side of the Antarctic Peninsula. However, it could be expected that the importance of this mechanism for influencing eastern Peninsula climate will remain comparatively weak [Schwerdtfeger, 1976].

[19] Finally, this mechanism may also explain other anomalies in local climate variation in other areas of the world with pronounced orography and where there are trends in the large scale winds.

[20] Acknowledgments. This work was supported by grants from NERC to the Centre for Polar Observation \& Modelling, University College London. The laboratory work was supported by the EEC contract 'Transnational Access to Major Research Infrastructures' HPRI CT 200100168.

\section{References}

Clark, P. A., and W. P. Hopwood (2001), One-dimensional site-specific forecasting of radiation fog. Part 1: Model formulation and idealised sensitivity studies, Meteorol. Appl., 8, 279-286.

Connolley, W. M., and H. Cattle (1994), The Antarctic climate of the UKMO unified model, Antarct. Sci., 6, 115-122.
Cullen, M. J. P. (1993), The unified forecast/climate model, Meteorol. Mag., 122, 81-94.

Hofmann, E. E., J. M. Klinck, C. M. Lascara, and D. A. Smith (1996), Water mass distribution and circulation west of the Antarctic Peninsula and including Bransfield Strait, in Foundations for Ecological Research West of the Antarctic Peninsula, Antarct. Res. Ser., vol. 70, edited by R. M. Ross, et al., pp. 61-81, AGU, Washington, D. C.

Hunt, J. C. R., H. Olafsson, and P. Bougeault (2001), Coriolis effects on orographic and mesoscale flows, Q. J. R. Meteorol. Soc., 127, 601-633. Hunt, J. C. R., A. Orr, D. Cresswell, and A. Owinoh (2004), Coriolis effects in mesoscale shallow layer flows, in Proceedings of the International Symposium on Shallow Flows, edited by G. H. Jirka and W. S. J. Uijttewaal, A.A. Balkena, Brookfield, Vt.

Jacobs, S. S., and J. C. Comiso (1997), Climate variability in the Amundsen and Bellingshausen Sea, J. Clim., 10, 697-709.

King, J. C. (1994), Recent climate variability in the vicinity of the Antarctic Peninsula, Int. J. Climatol., 14, 357-369.

King, J. C., and S. A. Harangozo (1998), Climate change in the western Antarctic Peninsula since 1945: Observations and possible causes, Ann. Glacol., 27, 571-575.

Kwok, R., and J. C. Comiso (2002), Spatial patterns of variability in Antarctic surface temperature: Connections to the Southern Hemisphere Annular Mode and the Southern Oscillation, Geophys. Res. Lett., 29(14), 1705, doi:10.1029/2002GL015415.

Marshall, G. J. (2002), Analysis of recent circulation and thermal advection in the northern Antarctic Peninsula, Int. J. Climatol., 22, $1557-1567$

Marshall, G. J. (2003), Trends in the Southern Annular Mode from observations and reanalyses, J. Clim., 16, 4134-4143.

Marshall, G. J., V. Lagun, and T. A. Lachlan-Cope (2002), Changes in Antarctic Peninsula tropospheric temperatures from 1956 to 1999: A synthesis of observations and reanalysis data, Int. J. Climatol., 22, $291-310$.

Ólafsson, H. (2000), The impact of flow regimes on asymmetry of orographic drag at moderate and low Rossby numbers, Tellus Ser. A, 52, $365-379$.

Ólafsson, H., and P. Bougeault (1997), The effect of rotation and surface friction on orographic drag, J. Atmos. Sci., 54, 193-210.

Schwerdtfeger, W. (1976), Notes and correspondence: Changes of temperature field and ice conditions in the area of the Antarctic Peninsula, Mon. Weather Rev., 104, 1441-1443.

Shuman, C. A., and C. R. Stearns (2001), Decadal-length composite inland west Antarctic temperature records, J. Clim., 14, 1977-1988.

Smith, R. B. (1989), Hydrostatic flow over mountains, Adv. Geophys., 31, $59-81$.

Turner, J., S. R. Colwell, and S. A. Harangozo (1997), Variability of precipitation over the coastal Antarctic Peninsula from synoptic observations, J. Geophys. Res., 102, 13,999-14,007.

van den Broeke, M. (2000), The semi-annual oscillation and antarctic climate. Part 4: A note on sea ice cover in the Amundsen and Bellingshausen Seas, Int. J. Climatol., 20, 455-462.

Vaughan, D. G., G. J. Marshall, W. M. Connolley, J. C. King, and R. Mulvaney (2001), Climate change-Devil in the detail, Science, 293, $1777-1779$

D. Cresswell, J. C. R. Hunt, M. Light, and A. Orr, Centre for Polar Observation and Modelling, Department of Space and Climate Physics, University College London, Gower Street, London WC1E 6BT, UK. (ao@cpom.ucl.ac.uk)

G. J. Marshall, British Antarctic Survey, Cambridge, UK.

J. Sommeria, Laboratoire des Ecoulements Géophysiques et Industriels/ CORIOLIS, CNRS, Grenoble, France.

C. G. Wang, Department of Meteorology, University of Reading, Reading, UK. 